\title{
Research on Distortional Buckling of Steel I-Section Beams
}

\section{Tadeh Zirakian*and David Boyajian}

Department of Civil Engineering and Construction Management, California State University, Northridge, CA, USA

*Corresponding author: Tadeh Zirakian, Department of Civil Engineering and Construction Management, California State University, Northridge, CA, USA; Tel: +1-818-677-7718; E-mail: tadeh.zirakian@csun.edu

Received date: Sept 25, 2018; Accepted date: Sept 25, 2018;Published date: Oct 02, 2018

Copyright: (c) 2018 Zirakian T et al. This is an open-access article distributed under the terms of the Creative Commons Attribution License, which permits unrestricted use, distribution, and reproduction in any medium, provided the original author and source are credited.

\begin{abstract}
Distortional buckling of I-beams can occur in two lateral and restrained modes. Lateral-distortional mode of buckling is classified as local-global coupling which involves local changes in the cross-section geometry in addition to lateral displacement and twist. Restrained distortional mode of buckling, also, can occur due to applied restraints against rigid cross-sectional movements of one of the flanges. Compared to the two well-known local and lateraltorsional buckles, distortional buckling is relatively more complicated and less documented. Hence, further research work is still required to better understand and properly address this mode of buckling. This paper presents a review of some recently-published studies by the first author on the subject of distortional buckling of I-beams with the aim of providing some potential research avenues for fruitful future investigations.
\end{abstract}

Keywords: Distortional buckling; Steel I-beams; Prior research; Potential future research

\section{Introduction}

Distortional buckling of I-beams can occur in two lateraldistortional (Figure 1a) and restrained distortional (Figure 1b) modes.
Lateral-distortional buckling takes place in intermediate-length members with slender webs as a result of interaction between local and lateral-torsional modes of buckling. It is characterized by simultaneous distortion and lateral deflection of the cross-section. Restrained distortional buckling, on the other hand, can occur due to applied restraints against rigid cross-sectional movements of one of the flanges.
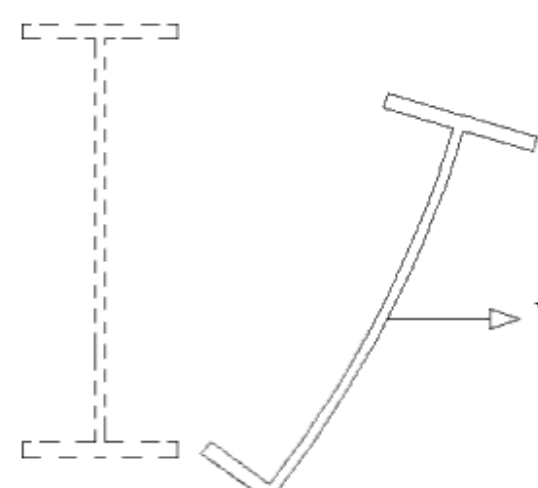

Web distortion

(a)

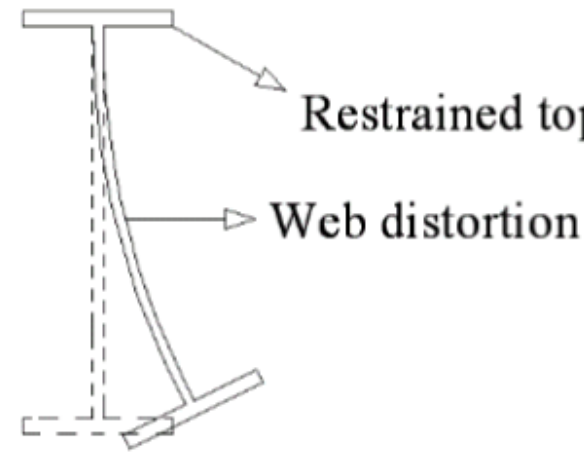

(b)

Figure 1: Distortional Buckling of I-beams: (a) Lateral-distortional mode (b) Restrained distortional mode.

Consideing the complexity of the distortional buckling mode, good comprehension and accurate evaluation of this phenomenon can result in the development of effective design guidelines and better performance of structures. This paper provides a review of the research work carried out by the first author over the past 15 years or so on the experimental verification of distortion in I-beams, numerical simulation using finite strip method, application of extrapolation techniques for accuate test-data analysis, and assessment of the AISC 360 Specification considerations. The objective is to demonstrate the different research avenues and provide useful indications for future experimental, numerical, and analytical investigations.

\section{Castellated and Plain-Webbed Beams}

Zirakian and Showkati reported a series of tests on castellated beams with the aim of experimentally verifying the web distortion in these structural members [1]. Web distortion was revealed experimentally through measurement of the deflection and strain at different locations of the instrumented specimens (Figure 2a). Zirakian and Showkati also, reported a test program on fabricated I-beams which were designed for experimental verification and investigation of distortion in doubly symmetric plain-webbed I-section beams [2]. Similarly, through detailed instrumentation, distortion of the web was experimentally verified in the two restrained (restrained distortional) 
Citation: Zirakian T, Boyajian D (2018) Research on Distortional Buckling of Steel I-Section Beams. J Steel Struct Constr 4: e109. doi:

and lateral (lateral-distortional) modes of buckling instability (Figure

2b).

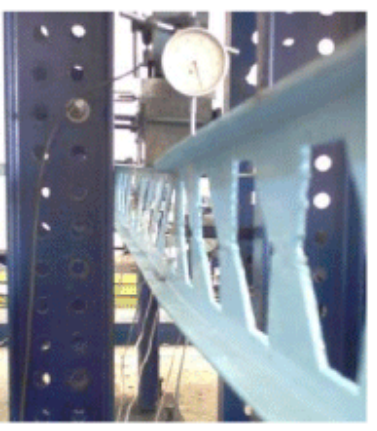

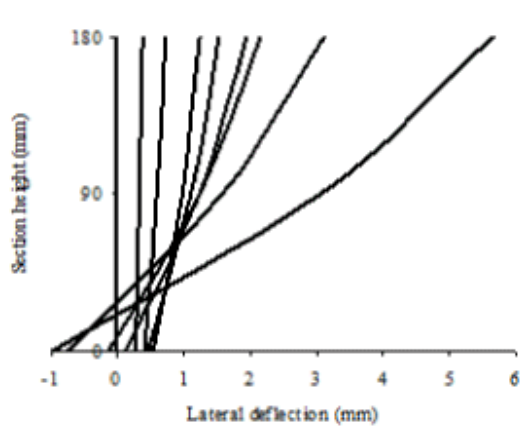

(a)
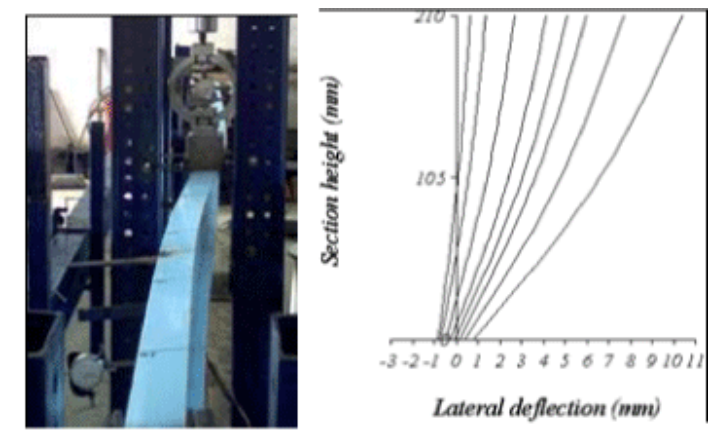

(b)

Figure 2: Distortional buckling of castellated and plain-webbed beams: (a) Castelled beam [1] (b) Plain-webbed beam [2].

\section{Finite Strip Analysis using CUFSM}

The analysis of elastic distortional buckling of simply supported Ibeams in uniform bending, using a finite strip analysis program, CUFSM, was performed by Zirakian [3]. CUFSM was originally developed to support research on the behavior and design of coldformed steel members. The accuracy of this program was shown to be good through comparison with established distortional buckling solutions. The buckling-response analysis of a typical I-beam in bending showed that the FSM solution does not provide distinct distortional minimum for I-sections. However, distortional buckling mode was identified through visual analysis of the deformed buckling mode shapes at intermediate half-wavelengths between local and lateral buckles, as shown in Figure 3.

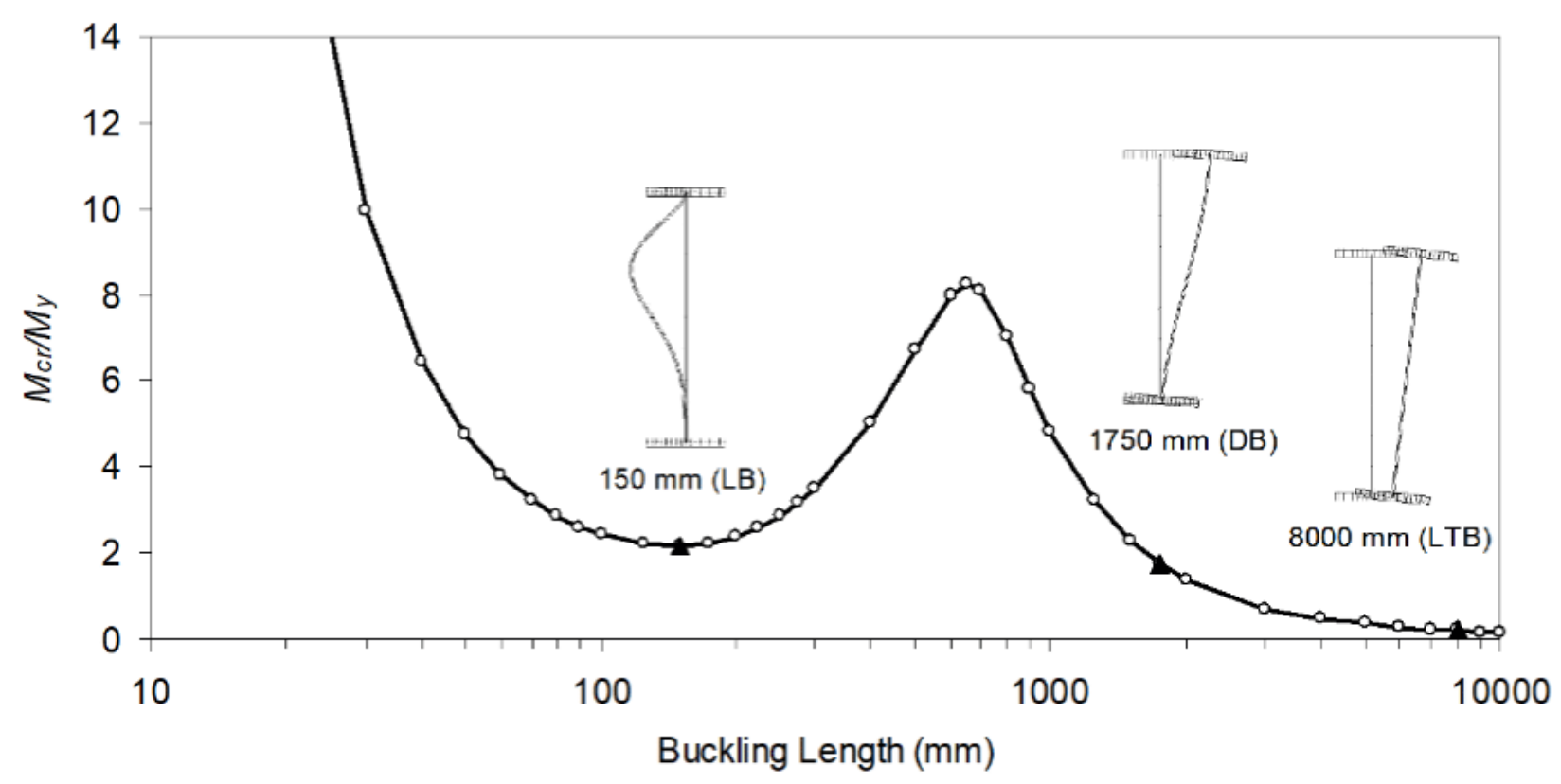

Figure 3: Finite strip analysis of a typical I-beam in bending [3].

\section{Application of the Extrapolation Techniques}

Extrapolation techniques are experimental methods used for predicting the critical buckling loads of structures undergoing lateral buckling, without having to test them to failure. To achieve this, it is necessary to have data relating load to a deformation characteristic. By plotting the results in a certain manner that a straight line resulted, it is be possible to determine the structure's buckling load. Zirakian used the South well, Modified, Massey, and Meck Plot methods to predict the critical buckling loads of some test I-beams undergoing inelastic lateral-distortional buckling (Figure 4a) [4]. The agreement between the extrapolated and the maximum test loads was found to be good. In 
a subsequent study, Zirakian showed that lateral displacement of Ibeams undergoing lateral-distortional buckling can be directly coupled with other deformation variables such as web transverse and longitudinal strains, vertical deflection, and angles of twist of top and bottom flanges [5]. On this basis, the South well, Massey, Modified, and Meck Plots were applied on the aforementioned deformation variables and satisfactory estimates were obtained for the critical buckling loads (Figure $4 \mathrm{~b}$ ). Later on, Zirakian and Nojoumi reported a study and demonstrated that web transverse and longitudinal strains, vertical deflection, and angles of twist of top and bottom flanges of Ibeams undergoing lateral-distortional buckling are two-by-two directly coupled and the application of the Meck Plot on each pair of these deformation variables may yield reliable predictions for the critical buckling load (Figure 4c) [6].

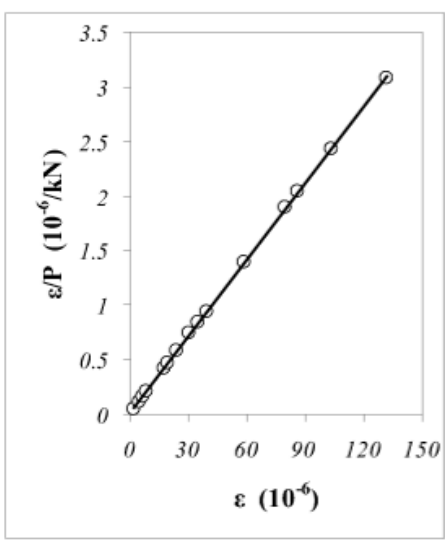

(a)

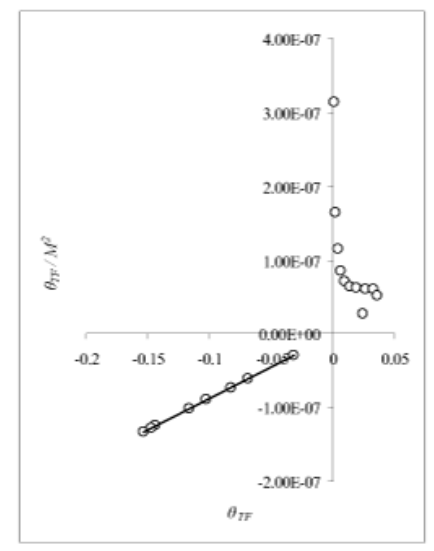

(b)

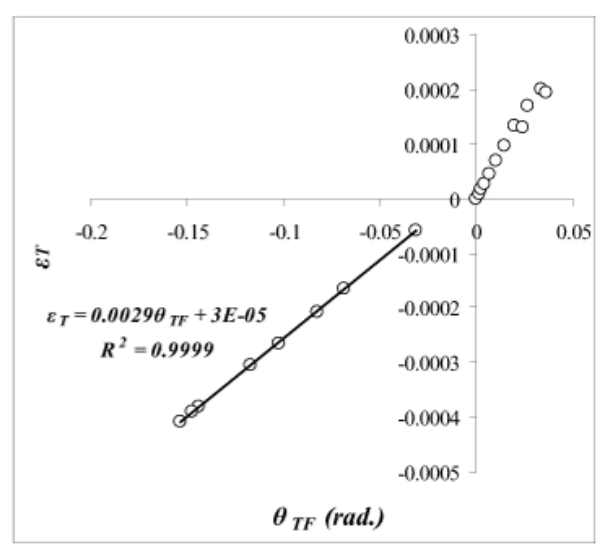

(c)

Figure 4: Research results from the application of the extrapolation techniques: (a) South well Plot [4] (b) Massey Plot [5] (c) Plot of web transverse strain vs. angle of twist of top flange [6].

\section{Evaluation of the AISC 360 Code considerations}

AISC 360-05 Specification accounted for the influence of web distortional flexibility on the lateral-torsional buckling resistance for slender-web I-section members through implicit use of $\mathrm{J}=0$ in the lateral-torsional buckling equations. Zirakian investigated the level of effectiveness and accuracy of this consideration in case of slender-web doubly symmetric I-shaped members within the elastic limit [7]. It was found that the assumption of $\mathrm{J}=0$ for doubly symmetric I-beams results in over conservative estimate of the buckling strength in some cases which may cause economic losses. In a subsequent study reported by Zirakian and Zhang, the efficacy of the AISC 360-05 code provisions was evaluated for the case of slender-web singly symmetric I-shaped members [8]. It was demonstrated that the code predictions are by and large conservative, and even overly conservative in some cases, which does not seem to be economically justifiable. As a result of these studies, it was recommended to conduct further experimental and theoretical studies to establish more efficient and optimal design rules to use as a specification check to avoid un-conservative and/or highly conservative design due to the influence of the web distortional flexibility.

\section{Concluding Remarks}

In this paper, some of the published research works undertaken by the first author on the dstortional buckling of I-beams were summarized. It is important to note that distorional buckling is by and large more complicated relative to the two well-known local and lateral modes of buckling. It is characterized by the distortion of the crosssection, especially the web of an I-section. On this basis, the main objective was to gather and briefly discuss the different experimental, numerical, and theoretical investigations as well as analysis tools in a single paper to provide the researchers and engineer with information regarding some of the fundamental steps taken towrds identification, analysis, and design for distortional buckling. In addition, this work introduced some areas of future research that will consequently result in acuarte performance assessment and efficient deisgn of I-section beams undergoing distortional mode of buckling.

\section{References}

1. Zirakian T, Showkati H (2006) Distortional Buckling of Castellated Beams. J Constr Steel Res 62: 863-871.

2. Zirakian T, Showkati H (2007) Experiments on Distortional Buckling of I-Beams. J Struct Eng ASCE 133: 1009-1017.

3. Zirakian T (2007) Elastic Distortional Buckling Analysis of Steel I-Beams Using CUFSM, Proc., 2007 Annual Conference of the Canadian Society for Civil Engineering (CSCE), Yellowknife, Northwest Territories, Canada.

4. Zirakian T (2008) Lateral-Distortional Buckling of I-Beams and the Extrapolation Techniques. J Constr Steel Res 64: 1-11.

5. Zirakian T (2010) On the Application of the Extrapolation Techniques in Elastic Buckling. J Constr Steel Res 66: 335-341.

6. Zirakian T, Nojoumi SA (2011) Elastic Lateral-Distortional Buckling of IBeams and the Meck Plot. Int J Struct Eng Mech 37: 297-307.

7. Zirakian T (2008) Elastic Distortional Buckling of Doubly Symmetric IShaped Flexural Members with Slender Webs. Thin-Walled Structures 46: 466-475.

8. Zirakian T, Zhang J (2012) Elastic Distortional Buckling of Singly Symmetric I-Shaped Flexural Members with Slender Webs. Int J Struct Stab Dyn 12: 359-376. 